before the Board, was not so much a matter of any opinion that will do injustice to any journal, figures, as that the showing for the graduates of but the truth of our convictions is, that some artithe Medical College of Virginia was far better than for any other school. The accurate percentage of rejections was $121 / 4$ - and the proportion for the other schools 25 to 33 per cent. The table published failed to state that last spring the Board licensed three young men as competent to practice medicine, who had been rejected by the Faculty of the College. We are not afraid to point to the ranks of the Army, Navy, and Marine Medical Service, for numbers of our Alumni, who have given satisfactory proof to the unprejudiced, that the work done by the Medical College of Virginia is not bad.

If Dr. Cullen misunderstood the charges made by THE JOURNAL, I assert that I have read them carefully and do understand them, and I em. phatically deny every statement, except so far as the students are referred to, supported and endorsed by one member of the Faculty in his individual capacity, and $I$ challenge the proofs that will convince an unpredjudiced profession. You have been misinformed Mr. Editor, we only desire that you should do us justice, and certainly the organ of the American Medical Association has a higher mission, than upon such flimsy evidence, to pursue a medical school, with a stainless record of half a century, in the spirit manifested by the recent articles which have appeared in its columns.

The weal of the profession and the admission to its ranks of men thoroughly prepared, is as earnestly desired by the Faculty of the Medical College of Virginia as any other men in the profession, and we stand ready to-day to sustain the Board in the prerequisite of a diploma, English examination, and lengthened term of study. Respectfully, J. N. UPSHUR, M.D., Prof. Mat. Medica, etc., and Secretary of the Faculty, Medical College of Virginia. 206 E. Grace St., Richmond, Va., Dec. 2I, 1888.

\title{
Infanticide.
}

Dear Sir:-The members of the medical profession must have felt embarrassed and humiliated at the exposure of abortionists by the Chicago Times. We heartily endorse the remarks of the Editor of ThE Journal on that subject. The profession cannot be consistent with the sentiments of this editorial and permit one of these men, or any known infanticidist, to remain within any medical society recognized by the American Medical Association. Nor should any member of the profession recognize or consult with one of them.

Permit your correspondent to say that our periodical literature has said but little, much too little, on this subject, to impress their readers with the enormity of this crime. We regret to express cles have been published by contributors to medical journals, that have come to my reading, that were not up to the standard of the opinion expressed by the Editor of ThE Journal. Correspondence has been published giving "The Best Mode of Producing Abortion," and one that I can recall in which the profession at large was asked to give a safe plan for this process. The public mind does not comprehend the great danger there is in producing this wrong act, nor is popular sentiment far enough advanced to comprehend the fact that it is murder to produce it. Every physician of much experience has been consulted on the propriety and even the necessity of doing this thing. Both fathers and mothers have been known to go to their physician with an argument to sustain their position, like the following: "Doctor, my wife is too weak to bear a family ;" and another confronts you with the plea that he is poor and not able to raise a large family, that he has enough and as many children as he can raise, that it would be better and nearer right to prevent the offspring from coming into the world alive than to let it be born to suffer and cause others to suffer.

This error and the long list of wrong opinions on this subject, can only be corrected by medical gentlemen, in their professional intercourse with their patrons. Educate the people to know the wrong and the crime, as well as the danger attending abortion, and but few applications will be made to the abortionist, and there will be no demand for his wicked service.

Indianapolis, Jan. 3, I889.

$$
\text { J. W. HERVEY, M.D. }
$$

\section{Medical Jurisprudence.}

Dear Sir:-The following case will probably interest your readers: One who holds himself out as a healer of diseases must, no matter what particular school or system he practices, be held to the duty of reasonable skill in the light of the present state of medical science. So held in a case of alleged clairvoyance. Nelson ws. Harrington, S. Ct. of Wisconsin, Nov. 8,$1888 ; 40$ Northwestern Reporter, p. 228.

Respectfully, M. D. EWELL.

Union College of Law, law department of the Northwestern University, Chicago, Jan. 3 , I889.

Personal.-Dr. E. A. Neeley, of Memphis, has retired from the editorial staff of that sterling journal, the Memphis Medical Monthly.

ThE CODE OF ETHICs.-At the recent meeting of the Tri-State Medical Association, our Code was sustained by a unanimous vote. 